Vol. 3, No. 2

Copyright (01999 by The Resilience Alliance

The following is the established format for referencing this article:

Pinkerton, E. 1999. Factors in overcoming barriers to implementing co-management in British Columbia salmon fisheries. Conservation Ecology 3(2): 2. [online] URL: http://www.consecol.org/vol3/iss2/art2/

Synthesis, part of Special Feature on Adaptive Management

\title{
Factors in Overcoming Barriers to Implementing Co-management in British Columbia Salmon Fisheries
}

Evelyn Pinkerton

\section{Simon Fraser University}

- Abstract

- Introduction

- Community Conservation Initiatives

o Two Regions with Special Partnerships and Selective Strategies

- Example 1: West Coast Vancouver Island (WCVI)

- Example 2: Lower Fraser River

- Summary Analysis of Key Barriers to Community Conservation Initiatives and Options for Overcoming Identified Barriers

o Category 1 Barriers

- Barrier: Government's Desire to Control Data

- Option: Data Sharing through Partnerships, Credible Third Parties, and Joint Data Banks

- Barrier: Government's Tendency to Conduct Single-species Management for Maximum Biological or Economic Yield

- Option: Engaging in the Scope of Activities Appropriate to the Problems Being Addressed

- Category 2 Barriers

- Barrier: Domination of Policy by Major Clients

- Option: Broadening the Base of Support for Innovation

- Barrier: Privatization Policies

- Option: Building Institutional Capacity for Alternative Solutions

- Conclusion

- Responses to this Article

- $\quad$ Literature Cited 


\begin{abstract}
Ten years of research and efforts to implement co-management in British Columbia fisheries have demonstrated that we lack neither good models nor the political will in communities to design and test local and regional institutions for successful involvement in various aspects of management. The barriers lie rather in the distrust and resistance of management agencies and the lack of broadly organized political support. The nature of the barriers and some of the elements of a successful approach to overcoming them are identified and discussed. The analysis is focused around the barriers encountered by two differently situated fishing communities or regions that have launched conservation initiatives through cooperation between local aboriginal and nonaboriginal fishing groups. In attempting to overcome the political barriers, the communities seek to develop expertise in selective fishing technology for more sustainable harvest, principled multistakeholder negotiation, marketing, shared databases, and preliminary ecosystem monitoring. The communities exemplify small- and medium-scale bottom-up approaches to adaptive management. The analysis shows the key and possibly unique contributions of processes at these levels, and suggests how they can be scaled up and linked to processes at other levels. Both types of analysis are largely missing in adaptive management theory, which has tended to focus on larger scale processes and to dismiss the potential of smaller scale ones to transform, expand, and link. This analysis focuses on salmon (Oncorhynchus spp.) fisheries of British Columbia, Canada, but the literature suggests that the findings have far broader applicability.
\end{abstract}

KEY WORDS: aboriginal-nonaboriginal partnerships, adaptive management, bottom-up approach, British Columbia, co-management, community-based management, fisheries, institutional barriers, Onorhynchus spp., salmon, selective fishing, stewardship.

Published September 7, 1999.

\title{
INTRODUCTION
}

There is increasing global recognition of five of the problems contributing to the degradation of aquatic ecosystems: (1) fishing strategies and technology that lead to high levels of by-catch and discarding of nontarget species (Alverson et al. 1994, NRC 1996); (2) lack of understanding of, and attention to, ecosystem linkages, including the importance of habitat (Nehlsen et al. 1991, Holling 1995, Pauly et al. 1998); (3) inappropriate and divisive institutional frameworks for management (Morgan 1997, Yaffee 1997); (4) loss of access by coastal fishing communities (UNCED 1992, FAO 1995); and (5) mass harvesting and processing strategies that miss opportunities to add value, and lead to overfishing (Pinkerton 1987, Galbraith 1995, Clapp 1998). These five problems are often linked: high by-catch fisheries and lower value mass production tend to be conducted by owners of vessels with no sociopolitical connection to, or long-term dependence on, the affected species or geographic region. Likewise diminished in this process are the local indigenous fishing communities with the potential to monitor and steward aquatic ecosystems sustainably. For several reasons, managers and policy makers have shown little ability to orient their programs toward ecosystem management and little 
inclination to take what are perceived as high risks on community-based co-management. Yet there may be no alternative but to take those risks, at least for species dependent on the health of watersheds and coastal zones. If remote, fishing-dependent communities with no economic alternatives are not directly involved as stakeholders and co-managers, they will eventually succumb to pressures to develop these areas for purposes other than fishing (Newton 1996).

Although both of these approaches, ecosystem management and community-based comanagement, are now widely accepted as promising, and often linked, means of achieving conservation and stewardship, work over the last decade has identified important barriers to building the necessary trust, support, and capacity (Pinkerton 1992, 1993, Gunderson et al. 1995, McCay and Wilson 1997). These barriers are particularly evident when communities attempt to launch conservation initiatives directed at solving some or all of the five problems just identified, but receive little support, or even opposition to their efforts. Two such initiatives are discussed here, illustrating the nature of some of the most promising initiatives, the nature of the barriers to them, and some of the options for an approach to overcoming these barriers. It is important for adaptive management theorists to consider initiatives at this small and medium scale because social learning scholars (e.g., Roling and Wagemakers 1998) believe that it is likely to be the scale at which the most transformative learning occurs. Many theorists also believe that expanding learning from this scale is the most powerful and enduring way to affect the change that needs to occur in the way people view the environment, and, in this case, the five recognized aquatic ecosystem problems.

\section{COMMUNITY CONSERVATION INITIATIVES}

Two regions with special partnerships and selective strategies

When local organizations solidify agreements among themselves (and usually also with governments) and regularize new practices in decision making, they are said to have created new institutions, in the sense of new arrangements and procedural rules for how decisions are made, and for how fishing and fish management is planned and conducted. Social scientists studying such co-management and self-management arrangements (e.g., Ostrom 1990, Pinkerton and Weinstein1995, Acheson and Wilson 1996) believe that many robust local-level institutions of this sort have endured or evolved for 400 years or more, sometimes with the active collaboration of central governments (e.g., Japanese fishing cooperatives), and sometimes without (e.g., communities on Lake Titicaca, Peru). A key premise emerging from the study of fisheries co-management arrangements around the world is that participants in locally based institutions that have a significant decisionmaking role have the potential to devise regulations that are more flexible, adaptable, and appropriate to specific situations than are those more generic ones crafted by centralized agencies. Working in tandem with central agencies, local bodies may be successful at devising sustainable harvest levels and promoting stewardship at the local level (Berkes 1989, Pinkerton 1989, Jentoft and McCay 1995). Institutional economists have found empirical evidence that the more local bodies devise locally appropriate rules, the fewer 
economic problems they suffer. This is because the locally crafted rules allow them to avoid or reduce appropriation externalities (overcapitalization and excess effort), technological externalities (gear conflicts and overcrowding), and assignment problems (allocation conflicts) (Schlager and Ostrom 1993). Although this potential is not automatically and universally realized under all conditions, the conditions have been favorable in the case of two British Columbia regions that have been undergoing considerable organizational and institutional development, and have also recently initiated significant conservation and stewardship measures.

In both regions appear two remarkable elements that are particularly conducive to conservation and the building of effective, flexible, and learning local institutions: an interest in selective fishing strategies, and partnerships between aboriginal groups and their neighbors. Here, I do not discuss the conditions for such initiatives to arise, but focus rather on their key characteristics and on what can impede or promote their progress after they have arisen.

\section{Example 1: West Coast Vancouver Island (WCVI)}

This region is in a situation typical of hinterlands worldwide that are remote from large river systems and fish-processing centers. Like other remote areas in British Columbia, the WCVI suffers from a long history of stock management policies that have resulted in the gradual erosion of wild local stocks (Roberts 1970) and the subsequent greater dependence of local communities on passing salmon stocks. The area has suffered equally from licensing and allocation policies that rewarded fishermen and companies with the greatest access to capital and the ability to combine many smaller licenses onto larger, more capital-intensive vessels with far greater fishing power (Hayward 1981, Marchak et al. 1987, Newton 1996). The fishing communities have seen that their work on stream enhancement and rehabilitation of local stocks will be continually undermined and overcome by these other trends if they do not develop the capacity to participate in fisheries planning in their region. Thus, this region is typical of fishing regions around the world that suffer from regional inequalities driven by similar forces, even in jurisdictions such as Norway, which have policies to suppress many of these tendencies (Jentoft and Mikalson 1987, Jentoft 1993).

The WCVI region may also be unusual in experiencing a long history of aboriginal cooperative exchange and mutual protection in pre-European times (Langdon 1976), a cooperation that endures currently through the Nuu-chah-nulth Tribal Council, the political body that unites this large region. A number of these WCVI communities have jointly developed a working model of the institutional arrangement that they favor, based on co-management models in Alaska and Washington State, which they researched, some in partnership with the author and other colleagues (Pinkerton et al. 1988, Pinkerton and Keitlah 1990). Their working model also draws from social movements and institutional innovations that they have experienced in logging and protected areas (resulting in the Clayoquot Sound Scientific Panel Recommendations for ecosystem management in one region of the WCVI and a regional board to implement the recommendations). Two fundamental principles emerged to guide the model: first, the need to develop an 
ecosystem approach to managing the territory, and second, the need to integrate aboriginal, sport, and commercial fisheries with all other uses. To build this working model, they engaged in long-term strategic planning and conducted a multiyear series of professionally facilitated workshops on how to construct a representative and accountable regional fisheries co-management board.

Importantly, this process became far more than the research, intersectoral exchange, and discovery aspects of constructing a local management board. The WCVI exemplifies transformation in fundamental attitudes, patterns of communication, and trust, all of which led to a willingness to partner, learn, and work together. Aboriginal and nonaboriginal communities especially, and, to a lesser extent, sport and commercial sectors, expressed regret about past enmities and made a fundamental commitment to work together to solve regional problems. This type of transformational learning is what Roling and Jiggins (1998) identify as particularly characteristic of smaller scale "learning communities." This level of reorganization of social systems has not been sufficiently appreciated in adaptive management theory, which tends to focus on larger scales and misses the power of local-level systems to change first themselves and then social systems at larger scales. In this case, the local institution has begun to change all of the regional governmental and nongovernmental institutions, and even aspects of provincial and central governance.

The region formed a steering committee, now called the Nuu-chah-nulth/Regional Aquatic Management Society (RAMS), composed of most of the major interest groups in the region, whose goals were to develop a management board in the traditional territory of the Nuu-chah- nulth (most of the WCVI). RAMS developed the initial institutional framework in terms of its relationship to government, and the basic representational and accountability principles that guide it in the process of forming the regional management body. RAMS has now been accepted by most federal and provincial governments as a group representative of the region, the group with whom they deal on fisheries matters. RAMS operates in complex ways in support of and sometimes as part of the aboriginal treaty-making process between the Nuu-chah-nulth and the federal and provincial governments.

An early project to begin implementing RAMS' goals was a selective harvesting initiative developed in partnership with the West Coast (Salmon) Trollers Association and the Fisheries Centre at the University of British Columbia in 1996. The West Coast Trollers Association, composed of the trollers (hook and line fishers) licensed to fish along the West Coast of Vancouver Island, identified the need to improve management through accurate and timely catch monitoring in-season. Because of the severely depressed nature of many Canadian coho salmon stocks, and the long-threatened Endangered Species Act listings of U.S.-bound coho and chinook salmon stocks in the United States (with whom Canada had a treaty to reduce interceptions), the trollers wished to be able to target more abundant Canadian sockeye or chum salmon stocks, while minimizing their by-catch of coho and chinook salmon. They were willing to pay for a catch-monitoring project out of their catch allocation (through sale of fish "off the top"). The project was to involve use of on-board low-cost, purpose-designed data keyboards linked to a Geographic 
Positioning System (GPS) and satellite communication hardware. Catch, CPUE, and catch location would be plotted daily on computer-generated maps at the Fisheries Centre at the University of British Columbia, and would enable an analysis of the best selective fishing strategies (e.g., in what locations can the fleet maximize the harvest of targeted species while minimizing by-catch). This information would be relayed to the regional body and to the public and government about a week later, with vessel identification removed from the public access version.

The federal government agency with the mandate to manage almost all aspects of Canadian marine fisheries is the Department of Fisheries and Oceans [DFO]. A desire by DFO to maintain exclusive control of the data was one barrier to implementing the community-based conservation initiatives. Despite recent new DFO leadership toward a more precautionary, conservation-based harvest and despite 1998 DFO policies promoting selective harvesting proposals, west coast Vancouver Island trollers' proposals to reduce by-catch through adaptive management experiments/research (such as identifying coho-free zones by analysis of historical fish delivery records combined with local knowledge of such zones) have been unsuccessful, beyond a token test fishery. DFO focused 1998 commercial fishing innovations on major gear alterations, intended to decrease mortality of fish encountered, rather than on fishing strategy modifications that reduce encounters with nontarget species (as in the troller-proposed experiment). This focus on gear alterations had the effect of locating the majority of acceptable innovations in commercial fishing in the large-vessel purse seine fleet. Salmon purse seiners are large, highly capitalized vessels that surround schools of salmon with a large net, which is then drawn tight at the bottom and hauled onto the desk. Most purse seiners are corporate owned or mortgaged (Cruickshank 1995; D. Cruickshank, personal communication 1997) and sell into the lower value, mass-produced canned salmon market. In contrast, the troll sector is smaller scale, mostly owner operated, and produces higher quality salmon for the fresh, frozen, and smoked market. Smaller scale owneroperated vessels tend to enjoy higher returns to capital investment, largely because of the high value of the product (Warriner 1987). The west coast trollers thus are allowed little opportunity to test their most important contributions to selective fishing in their traditional fishing areas. With the projected multiyear coho and chinook conservation closures of this area, the lack of response to selective fishing proposals will eventually spell the loss of commercial access to the traditional sockeye and chum fisheries of this area. With loss of access, local proposals to develop watersheds for non wild fishery uses may not be successfully stopped, and the institutional innovations and partnerships are put at risk in this area, even if/when the trollers are allowed to take their allocation in another area. The linkage between maintaining access and developing stewardship at the local level seems lost on DFO.

\section{Example 2: Lower Fraser River}

Institutional and conservation initiatives on the lower Fraser illustrate a different type of opportunity and also different barriers. Unlike the west coast of Vancouver Island, the small-scale gillnet fishermen of the lower Fraser were situated on the funnel through which swam the major sockeye salmon stocks that were receiving intense international 
management attention (e.g., they are a major point of negotiated allocation between the United States and Canada through the Pacific Salmon Treaty, and thus receive extra federal funds for monitoring). Because of concentrated abundance, the Fraser River gillnetters had the capacity to survive in one area with efficient techniques (high catch per unit of effort) and without major capital investments. Unlike the west coast Vancouver Island communities that suffered from regional inequalities, Fraser River communities suffer simply from their lack of political organization and marketing connections. But their small-scale operations have the advantages of location, efficiency, flexibility, and adaptability.

Governmental "mixed stock" harvest strategies for the Fraser had previously managed the fishery "actively" for a few major valuable and abundant stock groupings (e.g., Adams River sockeye salmon, which spawn in a tributary to the Fraser), at the expense of smaller stocks (e.g., small sockeye stocks) and other salmon species (coho, chinook, steelhead) taken as by-catch, which were overfished in the process (Slaney et al. 1996). In the early 1990s, concern for conservation of depressed upper Fraser River steelhead, coho, and chinook salmon stocks caused the DFO to close fall commercial gillnet fisheries targeting lower Fraser River chum salmon in the river mouth and lower river area. Catches of depressed stocks were also a concern in new aboriginal fisheries on the lower Fraser. In this case, it was DFO fishing time closures, and the fear that all lower Fraser commercial fishermen could lose access to their traditional allocation of chum that propelled innovation and another partnership between aboriginal and nonaboriginal fishermen on the lower Fraser in 1995.

The partnership was formed between the Fraser River Fishermen's Society (a small group of commercial gillnetters resident on the lower Fraser River) and the neighboring aboriginal Katzie First Nation, who had fished commercially on the lower Fraser for four generations. The partners believed that they stood a better chance of regaining access to chum salmon by working together. (Conversely put, if they were not able to agree about access, they believed they would have no chance of holding on to the traditional allocation to that area). They were aware of the selective live-capture beach seine technology used in DFO test fisheries, and in a northern British Columbia selective aboriginal fishery since 1992. They were also aware of aboriginal/nonaboriginal partnerships being piloted in other parts of B.C., especially through the work of the then treaty coordinator for the Katzie (Glavin 1996a, b). The hope of this initiative, like the Vancouver Island one, was that forming partnerships between local aboriginal and commercial groups could help to resolve local, and eventually province-wide, conflict between these sectors. In 1995, the partners obtained a DFO experimental license to conduct a selective live-capture beach seine fishery targeting abundant chum salmon stocks and releasing live the nontarget by-catch of depressed steelhead, coho, and chinook salmon.

Experimental licenses are issued by DFO for fisheries that are technologically (and sometimes sociologically) innovative. This fishery was technologically innovative in containing an important element of stock assessment research on the nontarget species, which were tagged as they were live-released (through the provincial Ministry of 
Environment Lands and Parks' radio-tagging program on live-released steelhead. MOELP had jurisdiction over steelhead in fresh water as a "sport" fish). Steelhead survival and migration were charted from the lower Fraser to the Thompson River. The fishery on the target species thus needs to be viewed more broadly than merely as a selective harvest. Information on the live-released by-catch in one year can be used to continually adapt the harvest location, timing, quantity, and technology to lower by-catch of nontarget species and to improve catch of target species. The highly controlled nature of this harvest (more controlled than most commercial fisheries in time, area, gear, and quantity limits) makes it very easy to monitor and to alter in response to information, an ideal adaptive management tool. In addition, because the license was "experimental," it was connected to detailed reporting and was very sensitive to what was learned.

DFO considered the 1996 results successful enough to invite other applicants for this type of fishery to operate in other parts of the river in 1997, particularly partnerships between aboriginal and commercial fishermen. Five types of innovative partnerships have resulted or been proposed in the second and third year of operation of the experimental license, including ones with other aboriginal groups farther upriver and downriver, ones using other selective technology (fishwheels, traps), ones on other species of salmon, ones combining aboriginal and experimental fisheries to reduce stress on the fish by avoiding multiple catch and release encounters of the same fish, and -- in habitat and stock restoration -- ones partnering with environmental groups, community-based NGOs, logging interests, and hydroelectric utilities. These innovations illustrate the type of learning, experimentation, and problem-solving creativity that is possible with a very small-scale "learning community" that is strong enough to link outward and upward to other partners in the larger system, and thus to transfer, energize, and spread the learning and the will to innovate. They also underline the role of flexibility, monitoring, and multiple partnerships in local experiments that link to larger scales.

The experimental fishery is opposed by most commercial and sport groups, who fear that this group will obtain a privileged allocation, in their minds unjustifiable because the group has no elected or representative structure. The group is also resented for cooperating with aboriginal groups on the river, whose rights to a special allocation of commercial fish are being challenged both politically and through the courts. They are feared by the major mass-production processors, who recognize that small-scale livecapture harvesting techniques could result in the development of new, higher value marketing channels. As a result, governmental support has been cautious and tentative. In 1998, DFO considered the fishery a "demonstration project" and paid the fishermen wages and gear development costs, allowing them to retain and sell surplus chum for aboriginal food and ceremonial purposes and eventually for project cost recovery (i.e., not for group profit). Although the lower Fraser group is less developed institutionally than RAMS, and its activities and partnerships are narrower in scope, its riverine bottleneck location has allowed it to progress further in selective fishing experiments based on gear modifications or innovations. The existence of multiple types of innovations arising in different parts of British Columbia (e.g., the WCVI and Fraser River) suggests that adaptive management theorists and managers should be alert to their possibilities and monitor their potential. It may be that the aspects identified above, 
which they have in common (and which are considered valuable by both learning and comanagement theorists ), are sufficient grounds for encouraging and monitoring their development.

\section{SUMMARY ANALYSIS OF KEY BARRIERS TO COMMUNITY CONSERVATION INITIATIVES AND OPTIONS FOR OVERCOMING IDENTIFIED BARRIERS}

The experience of these two British Columbia regions illustrates key barriers to community-based cooperative conservation initiatives, and thus barriers to the potential for bottom-up local and regional adaptive management experiments to expand and link to other levels. The barriers fit generally under the categories (1) distrust and resistance of management agencies, and (2) lack of broadly organized political support. After discussing each type of barrier, I summarize possibilities for overcoming them that have been noted in the literature on co-management initiatives.

\section{Category 1 barriers}

The distrust and resistance of management agencies was manifest in the following barriers, and can be overcome through the following options:

\section{Barrier: Government's desire to control data.}

This blocked free access to data sought in the west coast trollers' catch monitoring proposal. Sociologists have long noted the tendency of any organizational leadership to maximize its own power, control, and self-interest (Michels 1962). Scott (1998) observes that governments at all points on the political spectrum tend to quash the most positive, efficient, and sustainable innovations, if they suspect that these innovations could diminish their control. Viewed in the short term, government agencies that share data may indeed incur some political risks: they will have to acknowledge the degree of uncertainty in their stock assessment and harvest planning, and risk greater challenge to their decisions.

\section{Option: Data sharing through partnerships, credible third parties, and joint data banks.}

Viewed in the long term, new partners are likely to provide new resources in the form of moral, political, logistical (e.g., monitoring), and in-kind or even financial support. Partners also share the risk or blame by helping to decide what level of uncertainty and risk to public resources is acceptable. With or without partnerships, transparency in data, as required by the 1995 Food and Agriculture Organization (FAO) Fisheries Code of Conduct (of which Canada is a signatory) is to ensure that independent analysis of data and assumptions is possible by credible third parties, and that the public owners of the resource have access to basic information. The catch monitoring proposal on the west coast of Vancouver Island follows this model. Access to such information could have allowed the types of critiques that may have prevented the collapse of the northern cod 
(Finlayson 1994, Hutchings et al. 1997). A similar arrangement among the treaty tribes, the Washington Department of Fisheries, and the University of Washington has enabled the co-managing tribes and state management agency to agree on the validity of each others' catch data for the last 12 years, and to have publicly transparent analysis of the data while protecting the privacy of individual catch information. In this agreement, a neutral and credible third party (the university) enabled transparency in data collection and analysis. The University of Washington receives the fish tickets (sales slips) and enters them daily into the university computer during the fishing season. Data are available equally to the tribes and state, to university analysts, and increasingly to the public. This arrangement has advanced the ability of co-managing parties to solve their disagreements about preferred management actions, because they at least agree on the data.

While involving third parties provides one model for overcoming barriers when there is great distrust between partners, another approach that has been modeled in wildlife comanagement in the Canadian North (Kofinas and Eamer 1998) is an internet-accessible, shared data bank on environmental conditions, to which both government agencies and community-based experts contribute. In this case, enough trust and communication have been established under three settled aboriginal land claims and a co-management agreement that the parties use a worldwide web site to monitor agreed-upon indicators of ecosystem change, tourism activities, snow conditions, weather patterns, abnormalities, and unusual observations, harvest levels, movements of caribou through radio-collared individuals, and interpretations of causes of change by local experts. Variants on both of the approaches just discussed have been widely documented to assist disagreeing or competing parties in coming to agreements, and to assist agencies in meeting their public access and review obligations. An array of data sharing systems has provided flexible and adaptive tools for co-managers (Evans 1997: 65-80).

It is likely that the cost of local monitoring through a legitimate co-managing body would be lower than the cost of governmental monitoring alone, since legitimacy often elicits some degree of volunteerism, in-kind contributions, or independent fund raising (Pinkerton and Weinstein 1995). (However, this hypothesis cannot be tested in the two case studies just presented, because prior to co-management, there was inadequate governmental monitoring and/or data analysis, and current governmental monitoring is being further curtailed). Public data banks may provide another lower cost solution because of new technology and multipurpose uses and supports of such data banks. Thus, the concerns of adaptive management theorists (e.g., Lee 1993) about the formidable costs of monitoring ecosystems may be at least partially met by the willingness of key partners to monitor in a network of cooperation: a real possibility when the network functions as a partnership in discovery.

\section{Barrier: Government's tendency to conduct single-species management for maximum biological or economic yield vs. managing for a broader array of stocks and ecosystem linkages.}


Management agencies are notorious for piecemeal solutions to crosscutting problems (Holling 1995, Morgan 1997, Yaffee 1997). Yaffee's (1994) analysis of the U.S. Forest Service's 20-year history of resistance to recognizing multiple use (if it meant curtailing of old-growth harvests) illustrates the enormity of this resistance and the link to pressure group politics by the agency's major clients. It also suggests a tendency for resource management agencies to be captured by the mass production strategies of the largest claimants and the tendency of managers to find it more convenient to work with consistent data sources from a few large users. Finlayson (1994) found that this phenomenon helped to explain the northern cod collapse, and McCay and Wilson (1997) found that no fisheries management agencies had pursued ecosystem management beyond an initial interest. In a similar vein, James Scott (1998) found that government's simplification of species to be managed paralleled the cadastralization of land: when property rights were clearly mapped, simplified, and made transferable, production was more easily quantified and taxed. A few large-scale users are often considered more "manageable" than many small-scale users, even though (or perhaps because) the largescale users are more likely to have considerable political clout. Of course, single-species management for maximum yield, or even for optimum yield, fails to address issues of ecosystem linkages by not looking at fishing pressure in terms of the scope and scale needed to recognize when "fishing down the food webs" occurs (Pauly et al. 1998).

Canadian fisheries policies also have usually had the effect of transferring access rights away from small-scale commercial units to large-scale units with mass production strategies, linked to mass processing and markets (Marchak et al. 1987, Finlayson 1994, de Young et al. 1999, Walter et al. 1999). Under conditions of less conservationconstrained harvest and strong market demand, mass harvesting and processing could be economical, at least for some salmon species. Yet, with the recent doubling in Alaskan production of wild salmon (and the current buying of U.S. \$10 million of surplus canned salmon per year by the U.S. Department of Agriculture) mass-processed and massmarketed salmon are price takers with no hope of capturing the potential value of the resource. The major canners in both Alaska and British Columbia (sometimes the same entities) have shown little initiative in developing new value-added product forms and markets, and have historically demonstrated a predictable and widespread pattern of continuing to supply old mass markets that they control, even when returns would be higher in other markets or product forms over which they have less control (Pinkerton 1987, Clapp 1998). The 1998 DFO focus on large-scale commercial units (purse seiners) as the selective fishers of the future is also a choice to allocate fish to the massproduction processors with which the large-scale units are largely vertically integrated. In other words, even selective fishing as part of this strategy will not capture the maximum economic yield from the resource. Giving a majority role to such units is in fact risky, because the units with the highest investments will be the most compelled to maximize yield to be economical (Clapp 1998). Thus, the stated 1998 DFO policy of adopting a precautionary approach is fundamentally incompatible with DFO tendencies to manage for maximum biological and economic yield. At the same time, this policy does not address a fundamental problem identified at the outset: missing opportunities to add value. 


\section{Option: Engaging in the scope of activities that is appropriate to the problems being addressed.}

The west coast Vancouver Island communities are looking at selective fishing not only as an interim solution to reducing by-catch, but also as one of several means to identify and monitor ecosystem indicators. This approach is indicative of a commitment to a much longer time scale of learning. The indicators and spatial mapping of by-catch might also help them to identify relevant spatial scales at which management action is appropriate. Importantly, learning on this scale could assist in integrating the various management activities in which they are already involved (salmon freshwater habitat restoration, habitat monitoring, wild stock enhancement, developing new fisheries on other species such as mackeral that are implicated in the decline of local chinook salmon stocks, managing invertebrates, etc.) with those in which they wish to become involved (harvest regulation, stock assessment, research on local food webs, etc.): in other words, something approaching ecosystem management, much broader in scope than what conventional agencies are able to achieve. RAMS has recently been proposed as a pilot for a university-based modeling of multi-objective management, using multiple environmental accounts (Loucks and Scarfo 1998). Washington State tribal co-managers have engaged in this scope of management activities since the mid 1980s, although without explicitly taking an integrated approach or focusing on ecosystems.

The lower Fraser River communities are using their partnerships with other actors to address some of the same management scope issues. Through partnerships with others working to improve other areas of management (habitat monitoring, protection, and rehabilitation, involving urban pollution, land use practices, in-stream flow regulation by hydroelectric utilities, and value-added marketing), they attempt to extend the scope of attention relevant to the problem they address in their harvest management strategy.

\section{Category 2 barriers}

The lack of broadly organized political support was manifest in the following factors, and can be overcome through the following options:

\section{Barrier: Domination of policy by major clients.}

In the commercial sector, those having the greatest physical plant investments, the most highly capitalized vessels, and the longest history have been perceived as the major client group that DFO is supposed to serve. Thus, they have tended to have the greatest influence on fish harvesting policy, even though officially they are not supposed to own more than $12 \%$ of fishing licenses. This influence operates at several levels and is difficult and complex to document. In this discussion, I use one simple indicator, the transfer of personnel from DFO to various industry groups: in this case, the major processors' lobby group, the Fisheries Council of British Columbia. The most recent transfer (1997) took place within two weeks, but was claimed by federal officials not to be subject to the Treasury Board of Canada's conflict of interest and postemployment Code for the Public Service (Canada Treasury Board 1985), even though it occurred 
during a major policy debate on salmon allocation in which the DFO employee was centrally involved -- first for DFO, and then two weeks later for the major processors.

The multinational guided sport fishing industry has recently gained an almost equally dominant position as a client group, and appears to have reached agreement with the major processors on which species each will control. DFO's current policy (DFO 1998) is to reallocate coho and chinook from commercial to sport fisheries, guaranteeing sport allocation so that fishing lodges can make reservations for sport fishing clients well in advance. DFO emphasizes the economic value of the sport fishery, the importance of coho retention in the sport fishery (not requiring live release of all coho), and the fact that "regulatory uncertainty is the number one factor [negatively] affecting business prospects in the recreational fishery" (DFO 1998: 6). The head of DFO's sport fishing division left DFO in February 1998, and later in that month became director of the Sports Fishing Institute of British Columbia, the lobby group for the major guided sport fishing industry.

DFO's new allocation policy is causing major alarm in WCVI communities that have been rebuilding and enhancing some of the local coho stocks (which constitute 25-30\% of WCVI coho) to fishable levels. These WCVI communities are considering legal action and civil disobedience. The Sport Fishing Institute opposes community-based approaches, particularly the cooperation of local sport groups with commercial and aboriginal sectors at the local or regional level, because it claims the exclusive right to represent these groups. It also resents the fact that community-based groups raise questions about coho encounter and mortality rates in catch-and-release sport fisheries. Research on postrelease mortality in both sport and commercial fisheries in 1998 suggests that longer term mortalities may be significant (Gallaugher and Farrell 1999).

As previously noted, the strategies of both of DFO's major client groups are not compatible with flexible adaptive management, community-based management, or extracting the full potential value from the resource. (The issue of the relative value of commercial and sport fisheries is complex, has not been applied to small-scale valueadded commercial fisheries, and is outside the scope of this discussion). Hence, these actors attempt to maintain their position of policy influence by steering DFO away from these new directions. They constitute a major barrier to the adaptive management innovations described here.

\section{Option: Broadening the base of support for innovation.}

Linking political constituencies at the local level could be achieved by first forming an alliance between differently situated cases of co-management, such as these two examples, and eventually building toward a larger, coastwide constituency. Expansion of this constituency could eventually be part of the countervailing power (MacFarland 1987), which could counterbalance political pressures to maximize single-species yield and to allocate the majority of the catch to sectors that are disconnected from ecosystem and value-added concerns. 
Creating issue networks and coalitions brings in key actors from outside of these constituencies into a conversation about alternative policy, new models, and new technical information (Heclo 1978). Issue networks cut across conventional constituencies and create support for new ideas within government agencies, universities, and NGOs. Without support and coordination provided by issue networks and larger constituencies, the work of these communities will be contained, isolated, and marginalized -- and will ultimately fail. The joining of overlapping networks around the growing awareness of coho stock collapses in 1997-1998 demonstrated some aspects of an issue network. For example, a series of meetings brought together coastwide fishermen's organizations, coastal fishing community leaders, the Coastal Communities Network, academics, interior Fraser River aboriginal groups, and a broader array of environmentalist groups than had previously cooperated. In 1999, an issue network has formed among environmentalists and First Nations who fear that DFO will place allocation to the sport fishery above conservation. First Nations on the upper Fraser River are discussing in-depth management issues with the Nuu-chah-nulth on the WCVI. Public education workshops by Simon Fraser University since 1995 have brought various fishermen opinion leaders coastwide together with academics and policy leaders to debate fisheries issues. Other community- based groups are beginning to get organized to form a unified political voice for more particular concerns, e.g., Streamkeepers (a DFOsponsored coastwide program of volunteers doing monitoring and restoration work on salmon habitat), the lobby against salmon farming, and DFO's community-based salmon enhancement projects. All of these formerly fractured constituencies have the potential to form a more unified issue network and eventually a coherent coalition with countervailing force. Many of these groups called for more selective fisheries in response to the 1998 deepening crisis in coho management, and can claim some role in effecting change.

This strategy depends not only on coordination with other local initiatives but also on successful and supportive links with institutions operating at a broader level. This is quite feasible in the case of a new, independent public watchdog body appointed in 1998 after years of public pressure: the Pacific Fisheries Resource Conservation Council. This council is charged with providing advice simultaneously to the public and to the Minister of Fisheries and Oceans on stock status and habitat, and with encouraging the free exchange of information. It has some ability to commission independent review and interpretation of data, and could play an important role in linking and facilitating the regional data banks discussed earlier. The Council's first report responds to the WCVI, Fraser River, and other cases of community-based conservation initiatives in British Columbia by recommending "carefully monitored experiments at the watershed level involving delegated authority to local communities and groups under the supervision of responsible agencies... [with] functions ranging from habitat protection to stock assessment to harvest management" (PFRCC 1999). Now that some confidence in this approach has been expanded to a higher level and given more public credibility, countervailing power is being created.

\section{Barrier: Privatization policies.}


Privatization policies favored by mainstream economists and increasingly adopted by DFO, alter access and place it eventually in the hands of private owners who do not necessarily have any commitment or attachment to a particular area or to the stocks using it. The most developed form of privatization, Individual Transferable Quotas (ITQs), was pioneered in British Columbia by a DFO employee who became Coordinator of the Groundfish Management Unit (which approves groundfish quotas). After leaving DFO 1 January 1998, he became a lobbyist and manager for the association of holders of black cod (Anoplopoma fimbria, a groundfish) ITQs later in the month. It is unclear at this point to what extent ITQ holders are, or will become, associated with the major processors. It is clear, however, that ITQs are not compatible with adaptive management and that ITQs are currently in favor with DFO, for some of the reasons discussed in the previous section.

A key driver in privatization policies is the defunding and downsizing of government agencies. As agencies struggle to maintain essential programs, they tend to look to their economists to define greater efficiencies and cost reductions. Economists have favored cost recovery programs from the fleet, which are most rapidly achievable through privatization and concentration of access rights, which may achieve greater economies of scale. Thus, the preferences of the bureaucracy, rather than conservation or ecosystem concerns, tend to drive privatization strategies increasingly toward higher levels of concentration of ownership.

Privatization programs in salmon (so far only transferable and combinable licenses for species and areas) may not take the form of ITQs, because of logistical difficulties with stock size variability and predictability. Instead, they will probably take the form of increased allocation to the corporate-owned fleet. This is reflected in corporate pressure to adopt a movable allocation formula, so that as the small-vessel owner-operator fleet licensed to fish in one area is reduced, the allocation may be moved to another area and be taken by the large-vessel corporate-associated fleet. If this principle is adopted, allocation will be fundamentally at variance with community-based adaptive management. Only if allocation is attached to areas will there be incentives for residents of areas to protect and enhance the health of the freshwater habitat and to harvest in a way that does not decrease stock abundance and diversity. Unfortunately, transferable license programs and fleet reduction programs have tended to remove licenses from the small-boat fleet in rural communities with less access to capital, and to concentrate licenses in fewer hands (Newton 1996, Walter et al. 1999).

\section{Option: Building institutional capacity for alternative solutions.}

The problems that are sometimes believed to be solved by privatization can also be solved by alternative means that address economic and ecological costs of management.

1) Resolving conflicts and building partnerships at the local level. In both regions, significant attempts to address conservation or ecosystem issues built upon partnerships among groups whose cooperation was urgently needed to implement the initiative. Forming the partnerships constituted conflict resolution in a situation that might 
otherwise have been plagued by several decades of intersectoral conflict and legal battles that would raise the costs of enforcement and rob energy from conservation, not to mention the absence of conservation initiatives. The breakthroughs in conflict resolution in British Columbia often occurred through regionally or locally facilitated processes. In one key facilitated process on the WCVI in spring 1997, participants did an exercise that produced expressions of regret from members of the nonaboriginal communities for their past opposition to aboriginals' constitutionally protected fishing rights. This was an attitudinal turning point between aboriginals and their neighbors, who began to speak of themselves as "we" thereafter, indicating a new level of trust, even though they had been actively cooperating for some time before this occurred.

2) Contributing precious social capital to management efforts. The historic breakthroughs in both regions in building cooperation among aboriginal people and their neighbors enabled these groups to do active problem-solving and contribute innovative solutions. The products of the agreements are valuable, and the agreements themselves are a precious resource, conceptualized by some scholars as social capital (Ostrom 1990). These agreements have allowed discussions around selective gear, value-added markets, and ecosystem management to be contributed in the last few years to regional workshops in several areas of the province. The partnerships formed are thus demonstrated, discussed, and dissemminated.

3) Building and building upon a stewardship ethic where it matters most. If such conservation initiatives do not emerge at the local and regional level, supported by local stewardship values and attitudes, there is little likelihood that they will emerge at a higher level. There is a recognition among most senior fisheries analysts that to achieve conservation will require nothing less than fundamental change in human attitudes and social structures (Alverson and Larkin 1993, Lawson 1993). Although institutions at a broader level such as the Pacific Resource Conservation Council will help, higher level institutions cannot be effective without values, attitudes, and institutional structures supporting conservation operating at the local level, where human behavior has the greatest impact on the resource.

\section{CONCLUSION}

This discussion has supported the premise that models exist in British Columbia that are adequate for launching co-management experiments, ones that could apply adaptive management principles at the local and regional level. Two types of ecosystem-based, community-based fisheries co-management initiatives were discussed, and the nature of barriers to them was analyzed. The barriers lay chiefly in the ways in which the new initiatives challenged or appeared to challenge the existing management system, either because they ran counter to current government policies in data control, fleet concentration, and privatization, or in the production, processing, and marketing strategies of the corporate fishing and processing sector, and the major sportfish industry. The discussion drew from existing cases in the literature that show both what types of barriers exist and what types of adaptive strategies have been used elsewhere for 
overcoming these political barriers, arguing that the same strategies could be used successfully in British Columbia. Strategies included regional data sharing and banking with credible third parties, engaging in the scope of activities that is appropriate to the problems being addressed, building issue networks and coalitions, linking local efforts to regional and provincial-scale institutions, and building institutional capacity for alternative solutions. The discussion was situated in the context of the need for reforms of this type, because initiatives propose to address the five core problems identified at the outset through (1) reducing by-catch and nonsustainable fishing practices, (2) linking harvest strategies to efforts to understand habitat and ecosystems, (3) integrating at the local or regional level the divisive institutional frameworks for management, (4) maintaining enough stake in the resource by coastal fishing communities that they will fight to preserve adjacent salmon habitat and maintain their potential to contribute to conservation in other ways that are not possible for central agencies, and (5) increasing the incentive to develop value-added markets, which in turn can reduce pressures to overharvest.

The discussion showed that local and regional co-management initiatives can apply adaptive management principles in a manner that induces profound transformative learning and that can be spread to the broader and higher levels usually associated with case studies of adaptive management. This finding suggests that adaptive management theory and practice should also focus on smaller scales and lower levels of governance as key building blocks. The two co-management systems described here display many of the qualities identified as key by adaptive management theorists (e.g., Lee 1993, Holling 1995), including: system flexibility, long-term planning horizons, broadly defined goals, partnerships, professional facilitation, a research and experimentation posture, willingness to monitor, and civic science through shared databases. In addition, these local co-management systems demonstrate transformative learning, a quality identified as key by social learning theorists (Roling and Wagemakers 1998), and the potential for producing higher product value and commitment to resource stewardship over development.

\section{RESPONSES TO THIS ARTICLE}

Responses to this article are invited. If accepted for publication, your response will be hyperlinked to the article. To submit a comment, follow this link. To read comments already accepted, follow this link.

\section{LITERATURE CITED}

Acheson, J., and J. Wilson. 1996. Order out of chaos: the case for parametric management. American Anthropologist 98(3): 579-594.

Alverson, D. L., M. H. Freeberg, S. A. Murawski, and J. G. Pope. 1994. A global assessment of fisheries bycatch and discards. Food and Agricultural Organization 
Fisheries Technical Paper 339. Food and Agriculture Organization of the United Nations (FAO), Rome.

Alverson, D. L., and P. A. Larkin. 1993. Fisheries: fisheries science and management -century 21. Pages 150-167 in C. W. Voigtlander, editor. The state of the world's fisheries resource. Proceedings of the World's Fisheries Congress, Plenary Sessions. Oxford and IBH Publishing, Oxford, UK.

Berkes, F., editor. 1989. Common property resources. Ecology and community-based sustainable development. Belhaven, London, UK.

Canada, Treasury Board. 1985. Conflict of interest and post-employment code for the public service. Personnel Policy Branch, Treasury Board Secretariat, Minister of Supply and Services, Ottawa, Ontario, Canada.

Clapp, R. L. 1998. The resource cycle in forestry and fishing. Canadian Geographer 42(2): 129-144.

Cruickshank, D. 1995. A Commission of Inquiry into licencing and related policies of the Department of Fisheries and Oceans. Second edition. United Fishermen and Allied Workers Union, Vancouver, British Columbia, Canada.

DFO (Department of Fisheries and Oceans). 1998. An allocation framework for Pacific salmon. A new direction: the second in a series of papers from Fisheries and Oceans Canada. Vancouver, British Columbia, Canada.

de Young, B., R. M. Peterman, A. R. Dobell, E. Pinkerton, Y. Breton, A. T. Charles, M. J. Fogarty, G. R. Munro, and C. Taggart. 1999. Canadian marine fisheries in a changing and uncertain world. Canadian Special Publication of Fisheries and Aquatic Sciences Number 129, <>1999

FAO (Food and Agriculture Organization of the United Nations). 1995. The code of conduct for responsible fisheries. Adopted by the 28th Session of the FAO conference, October 1995. Accessible at:

http://www.fao.org/WAICENT/faoinfo/fishery/FIconde.htm.

Finlayson, A. 1994. Fishing for truth. Institute of Social and Economic Research, St. Johns, Newfoundland, Canada.

Galbraith, J. K. 1995. The world economy since the wars. Mandarin, London, UK.

Gallaugher, P., and A. P. Farrell.. 1999. Physiological indicators of stress of capture and mortality risk in commercial non-retention fisheries. Report to the Department of Fisheries and Oceans, Vancouver, British Columbia, Canada. 
Glavin, T. 1996a. Dead reckoning. Confronting the crisis in Pacific fisheries. Douglas and McIntyre, Vancouver, British Columbia, Canada.

. 1996b. This ragged place. Travels across the landscape. Newstar, Vancouver, British Columbia, Canada.

Gunderson, L. H., C. S. Holling, and S. S. Light, editors. 1995. Barriers and bridges to the renewal of ecosystems and institutions. Columbia University Press, New York, New York, USA.

Hayward, B. 1981. The B. C. salmon fishery: a consideration of the effects of licencing. B. C. Studies 50: 39-51.

Heclo, H. 1978. Issue networks and the executive establishment. Pages 87-124 in A. King, editor. The new American political system. American Enterprise Institute, Washington, D.C., USA.

Holling, C. S. 1995. What barriers? What bridges? Pages 3-34 in L. H. Gunderson, C. S. Holling, and S. S. Light, editors. Barriers and bridges to the renewal of ecosystems and institutions. Columbia University Press, New York, New York, USA.

Hutchings, J. A., C. Walters, and R. Haedrich. 1997. Is scientific inquiry incompatible with government information control? Canadian Journal of Fisheries and Aquatic Science 54: 1198-1210.

Jentoft, S. 1993. Dangling lines: the fisheries crisis and the future of coastal communities-- the Norwegian experience. Institute of Social and Economic Research, St. Johns, Newfoundland, Canada.

Jentoft, S., and B. J. McCay. 1995. User participation in fisheries management. Lessons drawn from international experiences. Marine Policy 19: 227-246.

Jentoft, S., and K. Mikalsen. 1987. Government subsidies in the Norwegian fisheries: regional development or political favouritism? Marine Policy 11(3): 217-228.

Kofinas, G., and J. Eamer. 1998. The arctic borderlands ecological knowledge cooperative: melding models to monitor a caribou commons. Presentation to the International Association for the Study of Common Property, Vancouver, B.C. Available electronically [check IASCP web site for 1998 papers through hess@indiana.edu; available in short term at www.sfu.ca/ iascp98].

Langdon, S. 1976. The development of the Nootkan cultural system. Paper given at the Northwest Coast Studies Conference. Simon Fraser University, Vancouver, British Columbia, Canada. 
Lawson, P. 1993. Cycles in ocean productivity, trends in habitat quality and restoration of salmon runs in Oregon. Fisheries 188: 6-10.

Lee, K. 1993. Compass and gyroscope: integrating science and politics for the environment. Island Press, Washington, D.C., USA.

Loucks, L., and K. Scarfo. 1998. Breaking the deadlock, building trust: framework for an Aquatic Conservation Trust. A strategy for environmental, social, cultural, and economic balance. West Coast Vancouver Island Regional Aquatic Management Society and Community Futures, Ucluelet, B.C.

McCay, B. J., and D. C. Wilson. 1997. "Ecosystem management" for U.S. forests and fisheries. Read to the Society for Applied Anthropology, Seattle, Washington, USA.

MacFarland, A. 1987. Interest groups and theories of power in America. British Journal of Political Science 17: 129-147.

Marchak, P., N. Guppy, and J. McMullan, editors. 1987. Uncommon property. The fishing and fish processing industries of British Columbia. University of British Columbia Press, Vancouver, British Columbia, Canada.

Michels, R. 1962. Political parties: a sociological study of the oligarchical tendencies of modern democracy. The Free Press, New York, New York, USA.

Morgan, G. 1997. Images of organization. New edition. Sage, Thousand Oaks.

Nehlsen, W., J. W. Williams, and J. A. Lichatowich. 1991. Pacific salmon at the crossroads: stocks at risk from California, Oregon, Idaho, and Washington. Fisheries 16: 4-21.

Newton, C. 1996. Salmon: building a sunrise industry, and analysis of the impacts of the Pacific Revitalization Program on salmon and communities, and recommendations for improvement. With contributions from the Pacific Salmon Alliance. Report prepared for the Pacific Salmon Alliance, P.O. Box 1080, 101-1001 W. Broadway Ave. Vancouver, British Columbia, Canada V6H 4G4.

NRC (National Research Council). 1996. Upstream. Salmon and society in the Pacific Northwest. Report of the Committee on Protection and Management of Northwest Anadromous Salmonids. National Academy of Sciences (USA), Washington, D.C., USA.

Ostrom, E. 1990. Governing the Commons. The evolution of institutions for collective action. Cambridge University Press, New York, New York, USA.

Pauly, D., L. Christensen, J. Dalsgaard, R. Froese, and F. Torres. 1998. Fishing down the food webs. Science 279: 860-863. 
PFRCC (Pacific Fisheries Resource Conservation Council). 1999. 1998-1999 Annual Report. PFRCC, 590-800 Burrard St., Vancouver, British Columbia, Canada. [available at www.fish.bc.ca.]

Pinkerton, E. W. 1987. Competition among B. C. fish processing firms. Pages 66-91 in P. Marchak, N. Guppy, and J. McMullan, editors. Uncommon property. The fishing and fish processing industries of British Columbia. University of British Columbia Press, Vancouver, British Columbia, Canada.

. 1989. Attaining better fisheries management through co-management -prospects, problems, and propositions. Pages 3-33 in E. W. Pinkerton, editor. Cooperative management of local fisheries: new directions for improved management and community development. University of British Columbia Press, Vancouver, British Columbia, Canada.

. 1992. Translating legal rights into management practice: overcoming barriers to the exercise of co-management. Human Organization 51(4): 330-341.

. 1993. Analyzing co-management efforts as social movements: the Tin-Wis Coalition and the drive for forest practice legislation in British Columbia. Alternatives 19(3): 33-38.

Pinkerton, E. W., and N. Keitlah. 1990. The Point No Point Treaty Council: innovations by an inter-tribal fisheries management co-operative. U.B.C. Planning Paper DP Number26. UBC School of Community and Regional Planning and Nuu-chah-nulth Tribal Council, Vancouver, British Columbia, Canada.

Pinkerton, E. W., S. Langdon, F. Cohen, N. Keitlah, W. Rees, P. Boothroyd, D. Lightly, and B. Green..1988. Launching a fisheries co-management pilot project. Phase I. Final Report. Department of Fisheries and Oceans, Vancouver, British Columbia, Canada.

Pinkerton, E. W., and M. Weinstein. 1995. Fisheries that work. Sustainability through community-based management. David Suzuki Foundation, Vancouver, British Columbia, Canada.

Roberts, M. 1970. The status of chum salmon stocks on the west coast of Vancouver Island, 1934-1968. Technical Report Number 3. Department of Fisheries and Oceans, Pacific Region, Vancouver, British Columbia, Canada.

Roling, N., and J. Jiggins. 1998. The ecological knowledge system. Pages 283-311 in N. G. Roling and M. A. E. Wagemakers, editors. Facilitating sustainable agriculture: participatory learning and adaptive management in times of environmental uncertainty. Cambridge University Press, Cambridge, UK. 
Roling, N. G., and M. A. E. Wagemakers, editors. 1998. Facilitating sustainable agriculture: participatory learning and adaptive management in times of environmental uncertainty. Cambridge University Press, Cambridge, UK.

Schlager, E. and E. Ostrom. 1993. Property Rights Regimes and Coastal Fisheries: An Empirical Analysis. Pages 13-41 in T. L. Anderson and R. T. Simmons, editors. The Political Economy of Custons and Culture: Informal Solutions to the Commons Problem. Rowman and Littlefield Publishers, Inc.

Scott, J. 1998. Seeing like a state. How certain schemes to impove the human condition have failed. Yale University Press, New Haven, Connecticut, USA.

Slaney, T. L., K. D. Hyatt, T. G. Northcote, and R. J. Fielden. 1996. Status of anadromous salmon and trout in British Columbia and the Yukon. Fisheries 21(10): 2034.

United Nations Conference on Environment and Development. 1993. Report of the United Nations Conference on Environment and Development, Rio de Janeiro 3-14 June 1992. United Nations, New York.

Walter, E., M. M'Gonigle, and C. McKay. 1999. Fishing around the law: The Pacific Salmon Management System as a structural infringement of aboriginal rights. Report R99-1. Faculty of Law and School of Environmental Studies, University of Victoria, British Columbia, Canada.

Warriner, K. 1987. Regionalism, dependence, and the B.C. fisheries: historical development and recent trends. Pages 326-349 in P. Marchak, N. Guppy, and J. McMullan, editors. Uncommon property. The fishing and fish processing industries of British Columbia. University of British Columbia Press, Vancouver, British Columbia, Canada.

Yaffee, S. L. 1994. The wisdom of the Spotted Owl. Policy lessons for a new century.. Island Press, Washington, D.C., USA.

.. 1997. Why environmental policy nightmares recur. Conservation Biology

11(2): 328-337.

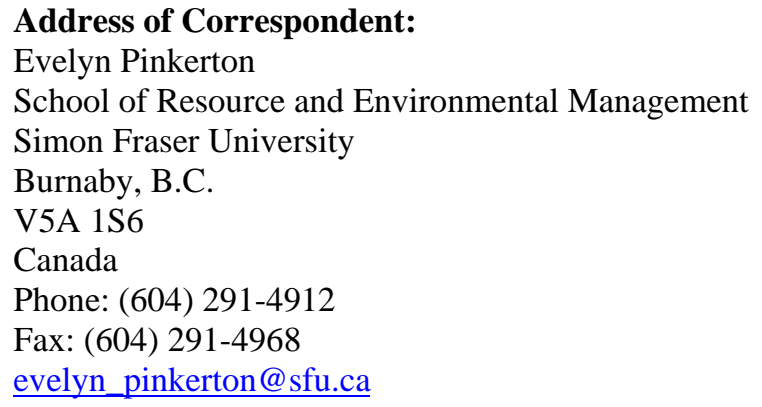

